\title{
Apoptotic effects of 7,8-dihydroxyflavone in human oral squamous cancer cells through suppression of Sp1
}

\author{
RA HAM LEE ${ }^{1 *}$, JAE-CHEON SHIN $^{3 *}$, KA-HWI KIM ${ }^{2}$, YUNG HYUN CHOI $^{4}$, \\ JUNG-IL CHAE $^{1}$ and JUNG-HYUN SHIM ${ }^{2}$
}

\author{
${ }^{1}$ Department of Oral Pharmacology, School of Dentistry and Institute of Oral Bioscience, BK21 plus, \\ Chonbuk National University, Jeonju 651-756; ${ }^{2}$ Natural Medicine Research Institute, Department of Pharmacy, \\ College of Pharmacy, Mokpo National University, Muan-gun, Jeonnam 534-729; ${ }^{3}$ Pohang Center for Evaluation of \\ Biomaterials, Pohang Technopark, Jigok-dong, Pohang, Gyeongbuk 790-834; ${ }^{4}$ Department of Biochemistry, \\ Dongeui University College of Oriental Medicine, Busan 614-052, Republic of Korea
}

Received September 16, 2014; Accepted October 15, 2014

DOI: $10.3892 /$ or.2014.3632

\begin{abstract}
Dihydroxyflavone (7,8-DHF) is a member of the flavonoid family and has recently been identified as a brain-derived neurotrophic factor mimetic that selectively activates tropomyosin-receptor kinase B with high affinity. The antioxidant and anticancer effects of 7,8-DHF have been reported. However, the pharmacological mechanisms of 7,8-DHF in oral cancer are unclear. Thus, we investigated the mechanisms of the antiproliferative action of 7,8-DHF on HN22 and HSC4 oral squamous cell carcinoma cell lines. We demonstrated that 7,8-DHF decreased cell growth and induced apoptosis in the HN22 and HSC4 cells through regulation of specificity protein 1 (Sp1) using the MTS assay, DAPI staining, Annexin V, propidium iodide staining, reverse transcriptionpolymerase chain reaction, immunocytochemistry, pull-down assay and western blot analysis. The results showed that the Sp1 protein bound with 7,8-DHF in the HN22 and HSC4 cells. Taken together, the results suggest that 7,8-DHF could modulate Sp1 transactivation and induce apoptotic cell death by regulating the cell cycle and suppressing antiapoptotic proteins. Furthermore, 7,8-DHF may be valuable for cancer prevention and better clinical outcomes.
\end{abstract}

Correspondence to: Professor Jung-Il Chae, Department of Oral Pharmacology, School of Dentistry and Institute of Oral Bioscience, BK21 plus, Chonbuk National University, Jeonju 651-756, Republic of Korea

E-mail: jichae@jbnu.ac.kr

Professor Jung-Hyun Shim, Natural Medicine Research Institute, Department of Pharmacy, College of Pharmacy, Mokpo National University, Muan-gun, Jeonnam 534-729, Republic of Korea

E-mail:s1004jh@gmail.com

*Contributed equally

Key words: 7,8-dihydroxyflavone, oral squamous cell carcinoma, apoptosis, specificity protein 1

\section{Introduction}

Oral squamous cell carcinoma (OSCC) is one of the most common types of malignant tumors in the world. Approximately 275,000 new cases of oral cancer occur each year, and OSCC accounts for more than $90 \%$ of the diagnosed cases of oral cancer (1-4). Oral cancer is the eighth leading cause of cancer-related mortality in men. The causes of oral cancer are tobacco, alcohol and ultraviolet light (5). Although conservative treatments for oral cancer, including surgery, radiation, and chemotherapy are well advanced, the 5 -year survival rate remains at $<50 \%$ (6). Surgical resection, radiotherapy and combination therapy with chemotherapy are typical OSCC therapeutic methods (7). Failure of treatment is often due to local and regional recurrence. However, due to improvements in local disease control, treatment failure of oral cancer occurs most frequently as metastasis (8). Therefore, new anticancer agents are urgently required to improve the therapeutic effect.

7,8-Dihydroxyflavone (7,8-DHF) is a flavonoid that exerts beneficial pharmacological and biochemical activities. 7,8-DHF has high selectivity and binding affinity to the tropomyosin-receptor kinase B (TrkB) receptor and activates downstream signaling $(9,10)$. 7,8-DHF is a powerful synthetic analog to brain-derived neurotrophic factor leading to robust activation of TrkB in the mouse brain (10). Flavonoids offer neuronal protection against oxidative stress due to glutamate toxicity (11) and show a spectrum of biological activities, including antiinflammatory, antioxidant, antimutagenic and anticarcinogenic effects (12-16). Therefore, the development of anticancer agents from flavonoids and other natural products is an important topic. However, little is known concerning the other biological effects of 7,8-DHF. In the present study, we investigated whether 7,8-DHF could modulate cell cycle progression and specificity protein (Sp) repression; thus, leading to the apoptotic death of OSCC.

$\mathrm{Sp}$ is a transcription factor that is generally expressed in all mammalian cells (17), and protein expression levels of $\mathrm{Sp1}$ are often greater in cancer cells than those in normal cells (18). 
Sp1 is a recently defined transcription factor (19) including $\mathrm{Sp} /$ Krüppel. These factors are involved in controlling the cell cycle, apoptosis, and angiogenesis and play an important role in other physiological processes (20-23). For example, Sp1 levels are higher in lung, breast, gastric, thyroid and colorectal cancers $(17,21,24)$. Moreover, Sp1 plays important roles in the carcinogenesis and metastasis of human tumors by regulating growth-related signal transduction, apoptosis, tumorsuppressor genes, cell cycle control molecules, oncogenes and angiogenesis-related factors $(25,26)$. Therefore, inhibiting Sp1 is an effective therapeutic strategy for preventing cancer.

We specifically examined the anticancer effect of 7,8-DHF on cell viability against the OSCC cell lines HN22 and HSC4 and identified proteins regulated by 7,8-DHF in the cells. We investigated whether expression of Sp1 and its downstream proteins and other important apoptotic proteins were altered by 7,8-DHF treatment. Our results provide evidence for the chemotherapeutic efficacy of 7,8-DHF in oral squamous cells. Our results suggest that 7,8-DHF has chemotherapeutic efficacy.

\section{Materials and methods}

Cell culture. The HN22 and HSC4 human OSCC lines were obtained from Dankook University (Cheonan, Korea) and Hokkaido University (Hokkaido, Japan), respectively, and were cultured in Hyclone Dulbecco's modified Eagle's medium (DMEM; Thermo Fisher Scientific, Logan, UT, USA) containing $10 \%$ heat-inactivated fetal bovine serum, and $100 \mathrm{U} / \mathrm{ml}$ each of penicillin and streptomycin (Thermo Fisher Scientific) at $37^{\circ} \mathrm{C}$ with $5 \% \mathrm{CO}_{2}$ in humidified air.

MTS cell viability assay. Cell viability was measured using the CellTiter 96 ${ }^{\mathrm{TM}}$ AQueous assay kit (Promega, Madison, WI, USA) according to the manufacturer's protocol. HN22 and HSC 4 cells were seeded in a 96-well plate for $24 \mathrm{~h}$ and then treated with 7,8-DHF $(5,10,20$ and $40 \mu \mathrm{M})$ for 24 and $48 \mathrm{~h}$. Cell viability was measured by adding the 3-(4,5-dimethylthiazol-2-yl)-5-(3-carboxymethoxyphenyl)-2-(4-sulfophenyl)2H-tetrazolium (MTS) dehydrogenase enzyme substrate and the electron coupling reagent phenazine methosulfate. The plates were incubated at $37^{\circ} \mathrm{C}$ in $5 \% \mathrm{CO}_{2}$ for $2 \mathrm{~h}$ after a $24 \mathrm{~h}$ or $48 \mathrm{~h}$ post-treatment with 7,8-DHF. Absorbance at $490 \mathrm{~nm}$ was recorded using a GloMax-Multi Microplate Multimode reader (Promega).

DAPI staining. The levels of nuclear condensation and fragmentation were observed by nucleic acid staining with DAPI. HN22 and HSC4 cells treated with 7,8-DHF were harvested by trypsinization, and fixed in $100 \%$ methanol at room temperature for $20 \mathrm{~min}$. The cells were seeded on slides, stained with DAPI $(2 \mu \mathrm{g} / \mathrm{ml})$, and monitored by FluoView confocal laser microscopy (Fluoview FV10i; Olympus Corp., Tokyo, Japan).

Propidium iodide (PI) staining. After $48 \mathrm{~h}$ of 7,8-DHF treatment, the HN22 and HSC4 cells were collected by centrifugation and combined with adherent cells. The cells were washed with cold phosphate-buffered saline (PBS), pooled, and centrifuged before being fixed in $70 \%$ ice-cold ethanol overnight at $-20^{\circ} \mathrm{C}$, and then treated with $150 \mu \mathrm{g} / \mathrm{ml}$ RNase A and $20 \mu \mathrm{g} / \mathrm{ml}$ PI (Sigma-Aldrich, St. Louis, MO,
USA). The stained cells were analyzed, and the distribution of the cells in different phases of the cell cycle was calculated using flow cytometry with a MACSQuant Analyzer (Miltenyi Biotec GmbH, Bergisch Gladbach, Germany).

Annexin V/7-AAD assay. The cells were seeded on a $100-\mathrm{mm}$ dish containing $5.2 \times 10^{5}$ cells/well for HN22 cells and $8.8 \times 10^{5}$ cells/well for HSC4 cells and treated with various concentrations of 7,8-DHF (10, 20 and $40 \mu \mathrm{M})$ for $48 \mathrm{~h}$. Both adherent and floating cells were harvested and washed once with PBS. The cells were incubated with Annexin V/7-AAD for $20 \mathrm{~min}$ at room temperature in the dark to detect apoptosis, followed by a $6 \mathrm{~h}$ incubation at $37^{\circ} \mathrm{C}$. Apoptotic and necrotic cells were analyzed by flow cytometry (Muse Cell Analyzer; Merck Millipore, Billerica, MA, USA) using the Muse Annexin V/7-AAD \& Dead Cell kit (MCH100105; Merck Millipore). The experiment was performed in triplicate.

Reverse transcription-polymerase chain $(R T-P C R)$ reaction. Total RNA was extracted from the cells using the TRIzol ${ }^{\circledR}$ reagent (Life Technologies, Carlsbad, CA, USA), and $2.5 \mu \mathrm{g}$ of RNA was used to synthesize cDNA using the HelixCript ${ }^{\text {TM }}$ first-strand cDNA synthesis kit (NanoHelix, Seoul, Korea). cDNA was obtained by PCR using $\beta$-actin-specific and Sp1-specific primers as described below under the following PCR conditions ( 35 cycles: $1 \mathrm{~min}$ at $95^{\circ} \mathrm{C}, 1 \mathrm{~min}$ at $56^{\circ} \mathrm{C}$ and $1 \mathrm{~min}$ at $72^{\circ} \mathrm{C}$ ). The $\beta$-actin primers were: forward, $5^{\prime}-\mathrm{GTG}$ GGG CGC CCC AGG CAC CA-3' and reverse, 5'-CTC CTT AAT GTC ACG CAC GAT TTC-3'; and the Sp1 primers were: forward, 5'-ATG CCT AAT ATT CAG TAT CAA GTA-3' and reverse, 5'-CCC TGA GGT GAC AGG CTG TGA-3'. PCR products were analyzed by $1 \%$ agarose gel electrophoresis.

Immunocytochemistry. HN22 and HSC4 cells were seeded onto sterilized glass coverslips on 6-well tissue culture plates for $24 \mathrm{~h}$ and incubated with 7,8-DHF for $48 \mathrm{~h}$. The cells were fixed and permeabilized with Cytofix/Cytoperm solution for $30 \mathrm{~min}$. The cells were blocked with $1 \%$ bovine serum albumin and then incubated with monoclonal $\mathrm{Sp} 1$ and cleaved caspase-3 antibody at $4^{\circ} \mathrm{C}$ overnight to express $\mathrm{Sp} 1$ and cleaved caspase-3. After washing with PBS containing $0.05 \%$ Tween-20 (PBST), Sp1 and cleaved caspase- 3 antibodies were reacted with a Jackson 488-conjugated anti-mouse and Jackson 647-conjugated anti-rabbit secondary antibody at room temperature for $1 \mathrm{~h}$ and mounted with Vectashield mounting medium to assess DAPI fluorescence (Vector Laboratories, Inc., Burlingame, CA, USA). The cells were visualized using a FluoView confocal laser microscope.

Pull-down assay. This method was previously described (27). Briefly, HN22 and HSC4 cell lysate $(500 \mu \mathrm{g})$ was reacted with Sepharose 4B or 7,8-DHF-Sepharose 4B (GE Healthcare Bio-Sciences, Piscataway, NJ, USA) matrix beads $(0.2 \mathrm{~g})$ in reaction buffer $[50 \mathrm{mM}$ Tris, $\mathrm{pH}$ 7.5, $5 \mathrm{mM}$ ethylenediaminetetraacetic acid (EDTA), $150 \mathrm{mM} \mathrm{NaCl}, 1 \mathrm{mM}$ dithiothreitol (DTT), $0.01 \%$ Nonidet P-40, $2 \mu / \mathrm{ml}$ bovine serum albumin, $0.02 \mathrm{mM}$ phenylmethylsulfonyl fluoride (PMSF) and $1 \mathrm{X}$ proteinase inhibitor cocktail]. After overnight incubation with gentle rocking at $4{ }^{\circ} \mathrm{C}$, the beads were washed five times with washing buffer (50 mM Tris, pH 7.5, $5 \mathrm{mM}$ EDTA, $150 \mathrm{mM}$ 


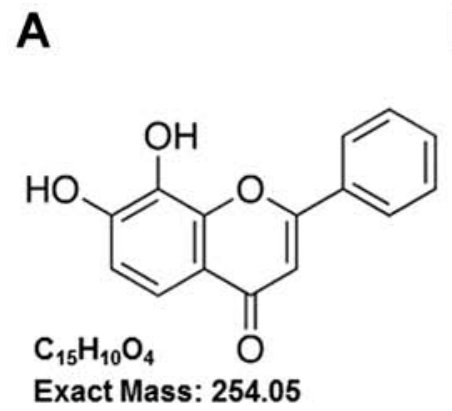
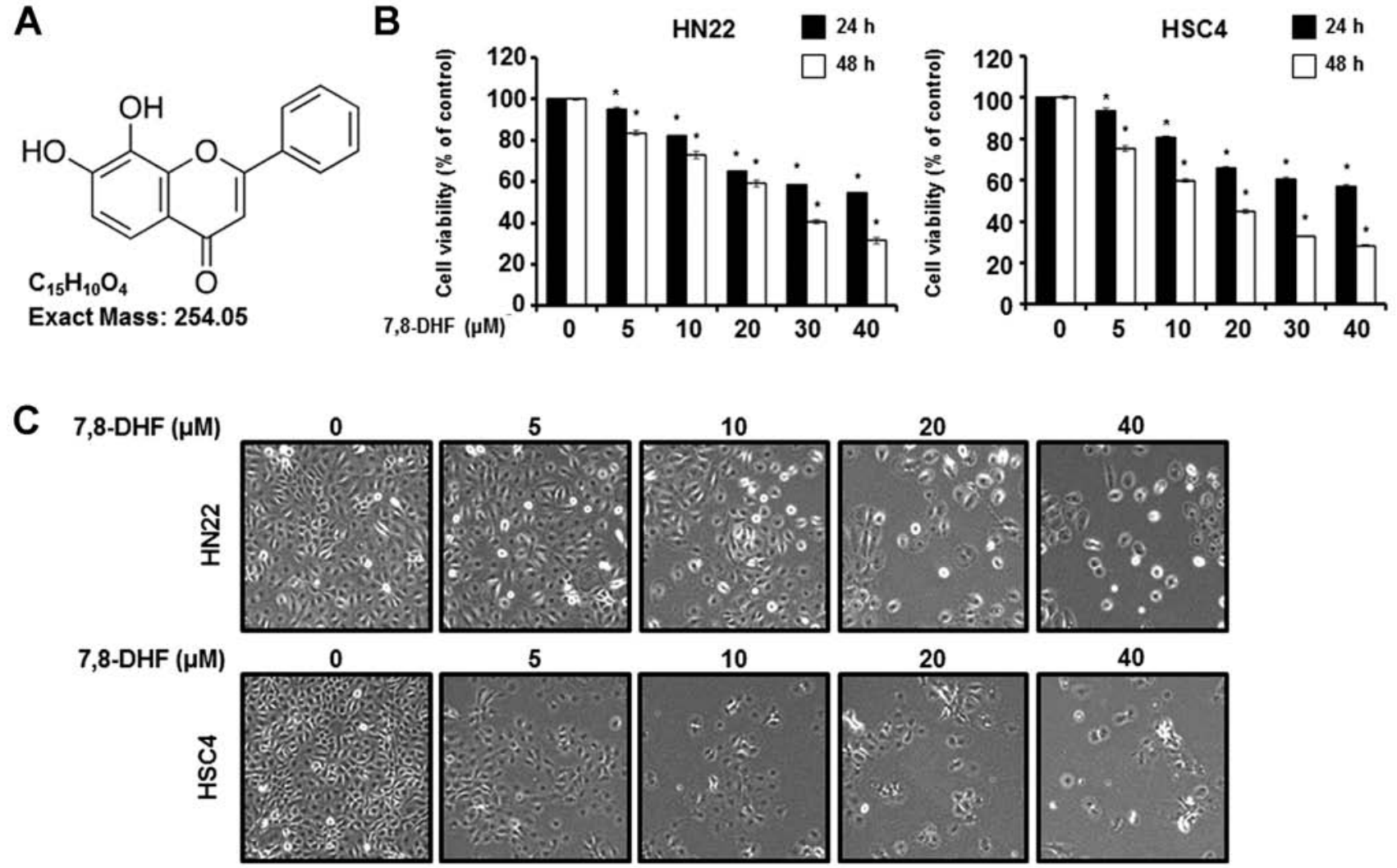
5
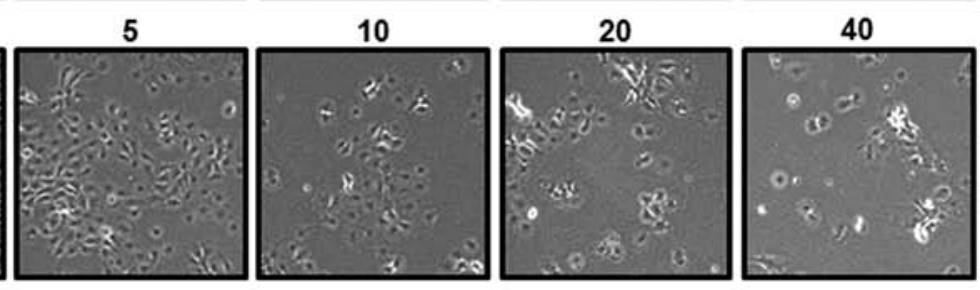

Figure 1. Effect of 7,8-DHF on the viability of oral squamous carcinoma cells. (A) Chemical structure of 7,8-DHF. (B) Cell viability in 7,8-DHF (5, 10, 20, 30, and $40 \mu \mathrm{M}$ )-treated HN22 and HSC4 cells was detected using an MTS assay kit. Data represent mean percentage levels \pm standard deviations. Significantly different compared with DMSO-treated control by the paired t-test ( $\mathrm{n}=3$; $\left.{ }^{\mathrm{P}} \mathrm{P}<0.05\right)$. (C) Morphological changes observed in the 7,8-DHF treated (5, 10, 20, 30, and $40 \mu \mathrm{M}$ ) or untreated $\mathrm{HN} 22$ and $\mathrm{HSC} 4$ cells 48 h post-treatment.

$\mathrm{NaCl}, 1 \mathrm{mM}$ DTT, $0.01 \%$ Nonidet P-40 and $0.02 \mathrm{mM}$ PMSF) and proteins bound to the beads were analyzed by western blot analysis.

Western blot analysis. HN22 and HSC4 cells were treated with 7,8-DHF (10, 20 and $40 \mu \mathrm{M})$ for $48 \mathrm{~h}$, washed with PBS, and harvested in ice-cold PRO-PREP ${ }^{\mathrm{TM}}$ protein extraction solution (Intron Biotechnology, Inc., Daejeon, Korea) containing a protease inhibitor. The extracted proteins were measured using a Pierce ${ }^{\circledR}$ BCA protein assay kit (Thermo Fisher Scientific). Equal amounts of protein were separated via $10 \%$ or $15 \%(\mathrm{v} / \mathrm{v})$ SDS-polyacrylamide gel electrophoresis and then transferred onto a polyvinylidene difluoride membrane. After blocking for $2 \mathrm{~h}$ at room temperature with 5\% non-fat dried milk in PBST containing $0.1 \%$ Tween-20, the membrane was incubated overnight at $4^{\circ} \mathrm{C}$ with the specific antibodies. Enhanced chemiluminescence western blotting was performed according to the manufacturer's instructions (Thermo Fisher Scientific).

Statistical analysis. Statistical significance was assessed using the Student's t-test. $\mathrm{P}<0.05$ relative to the control was considered significant.

\section{Results}

7,8-DHF inhibits cell viability and increases apoptosis in OSCC cells. The aim of the present study was to investigate the efficiency of 7,8-DHF to inhibit the growth of OSCC cells. The chemical structure of 7,8-DHF is shown in Fig. 1A. To confirm the growth inhibitory effect of 7,8-DHF on OSCC, HN22 and HSC4 cells were treated with 7,8-DHF, and cell viability was determined by the MTS assay. As shown in Fig. 1B, the MTS assay was performed after treatment with 7,8-DHF at various concentrations $(5,10,20,30$ and $40 \mu \mathrm{M})$ for 24 and $48 \mathrm{~h}$. Fig. $1 \mathrm{~B}$ shows that 7,8-DHF inhibited the viability of OSCC cells in a dose-dependent manner. The changes in the appearance of OSCC cells were observed with an optical microscope after $48 \mathrm{~h}$ (Fig. 1C). The apoptotic phenotype was a rounded cell, with cytoplasmic bleeding and an abnormal shape. These results indicate that 7,8-DHF inhibited the growth of human OSCC.

7,8-DHF causes $G_{1}$ phase cell cycle arrest of OSCC cells. Cancer cell proliferation can be suppressed by apoptosis, inducing cell cycle arrest or both. DAPI staining was performed to confirm the induction of apoptosis by 7,8-DHF in HN22 and HSC4 cells, as DAPI specifically stains nuclei. The results showed fragmented and condensed nuclei in cells treated with 7,8-DHF (10, 20 and $40 \mu \mathrm{M})$ for $48 \mathrm{~h}$ compared to that in the control (Fig. 2A). The cell cycle distribution was analyzed by FACS analysis. As shown in Fig. $2 \mathrm{C}$, a significant increase in the number of sub- $\mathrm{G}_{1}$ phase $\mathrm{HN} 22$ cells was observed $(11.2 \pm 1.4 \%$ in the presence of $10 \mu \mathrm{M} 7,8-\mathrm{DHF}, 31.0 \pm 2.3 \%$ in the presence of $20 \mu \mathrm{M} 7,8-\mathrm{DHF}$, and $44.0 \pm 2.6 \%$ in the presence of $40 \mu \mathrm{M}$ 7,8-DHF) compared with that of untreated control cells. An increase in the number of sub- $\mathrm{G}_{1}$ phase HSC4 cells was 
A

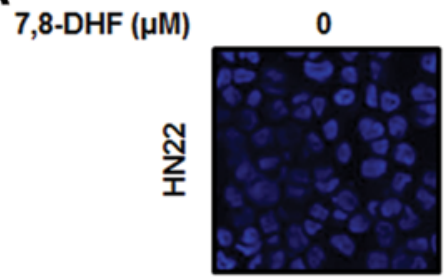

7,8-DHF ( $\mu \mathrm{M})$

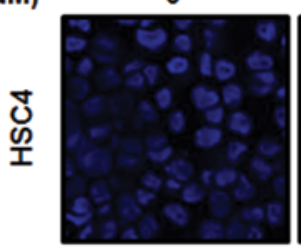

10

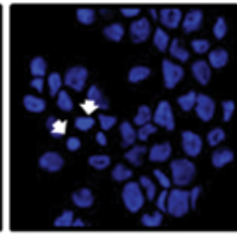

10

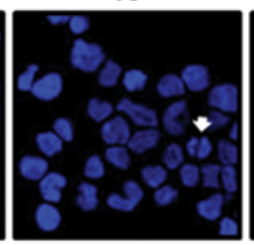

20

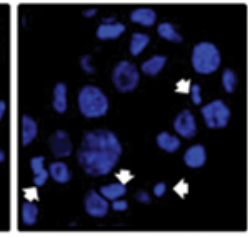

20

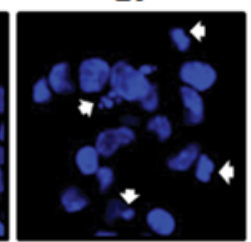

40

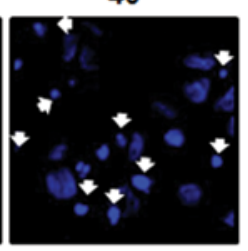

40

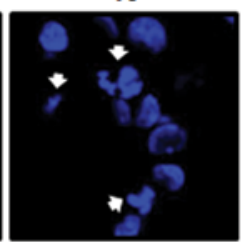

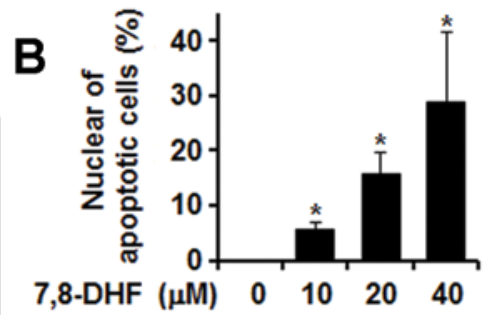

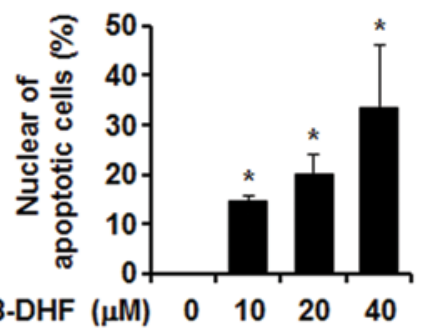

C

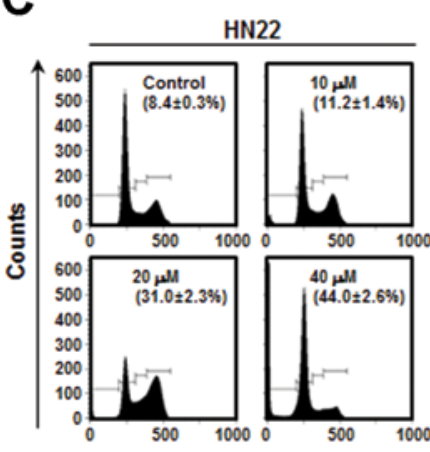

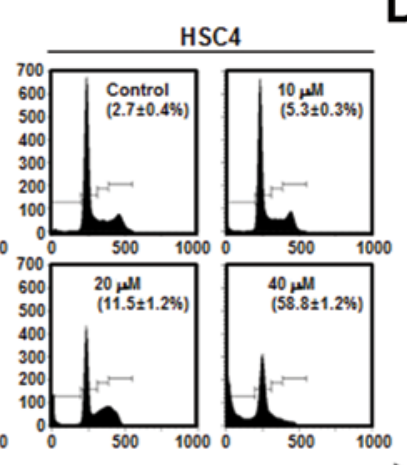

FL2-Area
D

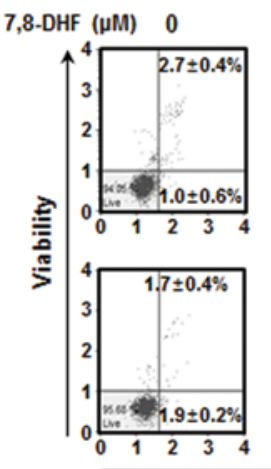

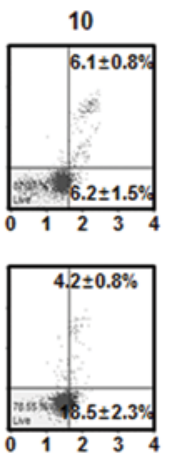
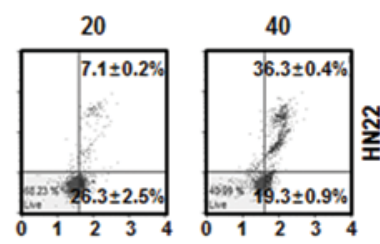

雍
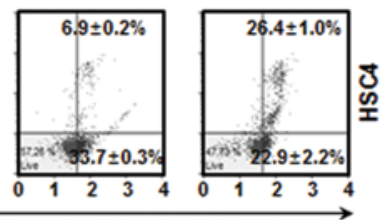

Annexin V

Figure 2. Apoptotic effect induced by 7,8-DHF in oral squamous cell carcinoma. HN22 and HSC4 cells were cultured without 7,8-DHF (control) or with 7,8-DHF $(10,20$ and $40 \mu \mathrm{M}$ ) for $48 \mathrm{~h}$. (A) Fluorescence microscopic (magnification, x200) images of DAPI-stained cells. White arrows indicate DNA fragmentation and nuclear condensation. (B) DNA fragmentation and nuclear condensation were quantified, and data represent the mean percentage levels \pm standard deviations ( $\mathrm{n}=3 ;{ }^{*} \mathrm{P}<0.05$ ). (C) HN22 and HSC4 cells were treated with 10, 20 and $40 \mu \mathrm{M} 7,8-\mathrm{DHF}$ or DMSO (vehicle), and the cells were washed, fixed, stained with propidium iodide (PI) and analyzed for DNA content by flow cytometry $48 \mathrm{~h}$ after treatment. The ratio of apoptotic cells was measured by flow cytometry after PI staining. (D) Quantitative detection of Annexin V/7-AAD positive cells was performed with the Muse Cell Analyzer. Cells stained with Annexin V only were defined as early apoptotic (lower right); Annexin V and 7-AAD double-stained cells were defined as late apoptotic (upper right).

also observed $(5.3 \pm 0.3 \%$ in the presence of $10 \mu \mathrm{M} 7,8$-DHF, $11.5 \pm 1.2 \%$ in the presence of $20 \mu \mathrm{M} 7,8$-DHF and $58.8 \pm 1.2 \%$ in the presence of $40 \mu \mathrm{M} 7,8-\mathrm{DHF}$ ) compared with that in the untreated control cells. Cells stained with Annexin V only were defined as early apoptotic and Annexin V (lower right) and 7-AAD double-stained cells were defined as late apoptotic (upper right). As shown in Fig. 2D, 7,8-DHF displayed marked effects to induce apoptosis of HN22 and HSC4 cells in a dose-dependent manner. Treatment of the HN22 cells with 10,20 and $40 \mu \mathrm{M}$ of 7,8-DHF for $48 \mathrm{~h}$ resulted in $6.2 \pm 1.5$, $26.3 \pm 2.5$ and $19.3 \pm 0.9 \%$ of early apoptotic cells and $6.1 \pm 0.8$, $7.1 \pm 0.2$ and $36.3 \pm 0.4 \%$ of late apoptotic cells, respectively. Similarly, treatment of HSC4 cells with 7,8-DHF also led to $18.5 \pm 2.3,33.7 \pm 0.3$ and $22.9 \pm 2.2 \%$ of early apoptotic cells and $4.2 \pm 0.8,6.9 \pm 0.2$ and $26.4 \pm 1.0 \%$ of late apoptotic cells at the same three concentrations as above, respectively. Apparently, 7,8-DHF-mediated apoptosis of HN22 and HSC4 cells, at least in part, contributed to its antiproliferative effects.

7,8-DHF suppresses Sp1 expression and binds with Sp1 in OSCC cells. As the Sp1 protein plays an important role in oncogenesis, a therapeutic agent that can effectively modulate the
Sp1 protein may be a suitable anticancer drug to suppress tumor progression (28). Both HN22 and HSC4 cells were treated with various concentrations of 7,8-DHF $(10,20$ and $40 \mu \mathrm{M})$ for $48 \mathrm{~h}$ to observe Sp1 protein expression levels. Fig. 3A and B shows a significant decrease in $\mathrm{Sp} 1$ protein expression levels in the HN22 and HSC4 cells in a dose-dependent manner. We also observed downregulation of the Sp1 protein in HN22 and HSC4 cells at $40 \mu \mathrm{M} 7,8$-DHF after different periods of time $(0,12$, 24, 36 and 48 h). Additionally, Sp1 mRNA was suppressed by 7,8-DHF in both HN22 and HSC4 cells (Fig. 3C). Consistent with these observations, the immunocytochemistry results revealed decreased Sp1 and increased cleaved caspase-3 levels in a dose-dependent manner in both the HN22 and HSC4 cell lines (Fig. 3D). We conclude that suppression of Sp1 by 7,8-DHF treatment leads to apoptotic cell death. Next, a pull down assay was performed to determine whether 7,8-DHF directly binds to Sp1. Fig. 4A and B showed that 7,8-DHF strongly suppressed Sp1 activity by directly binding to Sp1.

7,8-DHF modulates the factors concerned with cell cycle arrest or apoptosis of OSCC cells. In many previous studies, the downregulation of Sp1 was found to induce apoptosis, and Sp1 
A

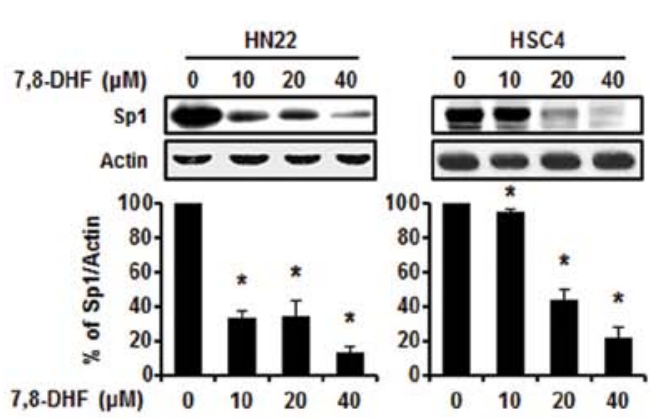

C

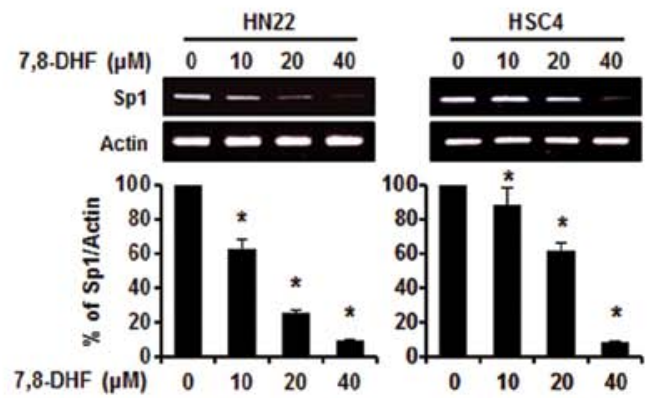

B
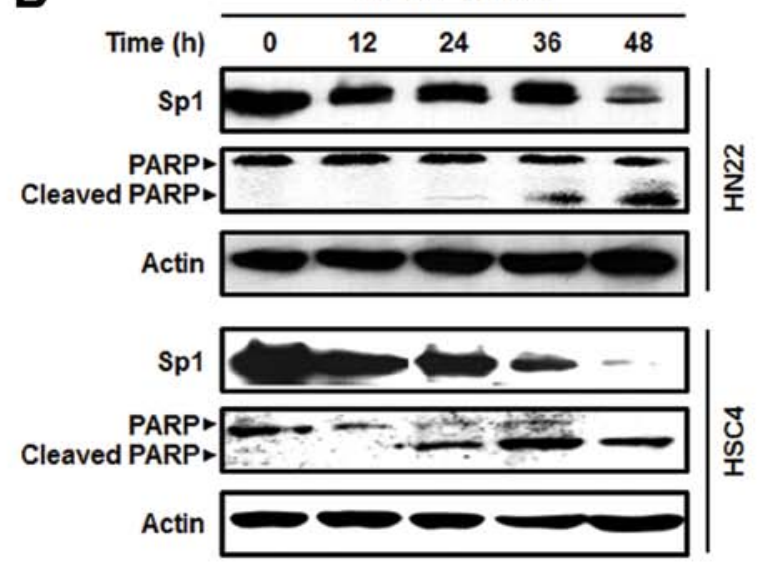

D

HN22, 7,8-DHF

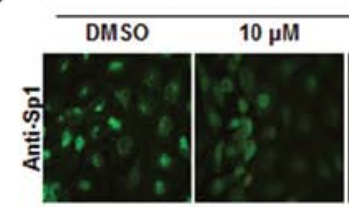
HN22, 7,8-DHF $40 \mu \mathrm{M} \quad \mathrm{IgG}$ Control $20 \mu \mathrm{M}$ \begin{tabular}{|l|l|}
\hline $40 \mu \mathrm{M}$ & \\
& \\
& \\
\hline
\end{tabular}

\begin{tabular}{|c|c|}
\hline DMSO \\
4 \\
4 & 4 \\
8 & 4 \\
8 & 4 \\
\hline
\end{tabular}

离
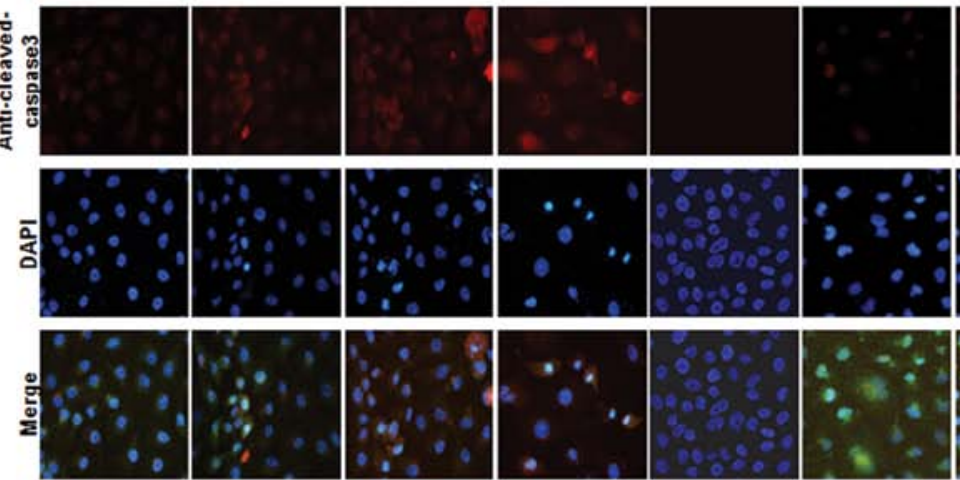

Figure 3. 7,8-DHF suppresses the Sp1 protein via apoptosis in oral squamous cell carcinoma. (A) HN22 and HSC4 cells were treated with 10, 20 and $40 \mu \mathrm{M}$ 7,8-DHF for $48 \mathrm{~h}$, whole-cell extracts were prepared, separated by SDS-PAGE gel electrophoresis, and subjected to western blotting with the Sp1 antibody. Actin was employed as the loading control. The histograms indicate the ratio of Spl to actin expression. (B) Experiments to assess time-dependent effects of 7,8-DHF on Sp1 and PARP were performed using HN22 and HSC4 cells treated with $40 \mu \mathrm{M}$ 7,8-DHF for 0, 12, 24, 36 and 48 h. (C) The effect of 7,8-DHF (10, 20 and $40 \mu \mathrm{M}$ ) on Sp1 mRNA after $48 \mathrm{~h}$. (D) Immunofluorescence microscopy was performed in 7,8-DHF-treated HN22 and HSC4 cells. HN22 and HSC4 cells were treated with different concentrations of 7,8-DHF $(10,20$ and $40 \mu \mathrm{M})$ for $48 \mathrm{~h}$ and the cells were immunostained with anti-Sp1 and anti-cleaved caspase-3. The signals were detected with Jackson 488-conjugated anti-mouse and Jackson 647-conjugated anti-rabbit secondary antibody. DAPI was used for nuclear staining.

was confirmed to be associated with cell apoptosis (28-30). We used western blot analysis to clarify the association between 7,8-DHF and Sp1-mediated apoptosis. We investigated the cell-cycle arrest proteins such as p27 and p21 and found increased levels following 7,8-DHF treatment. We also investigated cell proliferation and survival-related proteins such as cyclin D1, Mcl-1 and survivin, which were decreased in a dose-dependent manner following 7,8-DHF treatment (Fig. 5). We found a decrease in BID and $\mathrm{Bcl}_{\mathrm{xl}}$ and an increase in Bax expression. These proteins were associated with the apoptotic cell death induced by 7,8-DHF. Finally, cleaved caspase- 3 and cleaved PARP were induced by 7,8-DHF in a dose-dependent manner (Fig. 6). These results revealed that 7,8-DHF treatment of OSCC decreases Sp1, resulting in growth arrest and apoptotic cell death.

\section{Discussion}

Flavonoids demonstrate antiallergic, antiinflammatory, antioxidant, and anticancer effects. They also regulate enzyme 
A

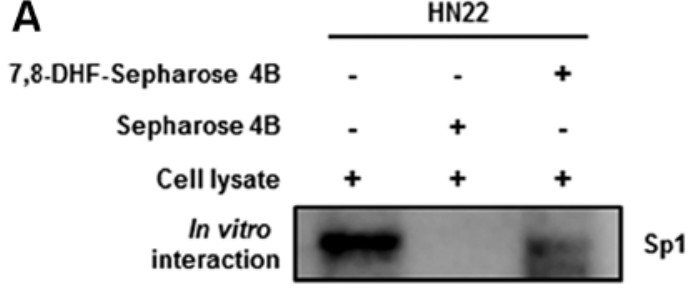

B

7,8-DHF-Sepharose 4B

Sepharose 4B

Cell lysate $\quad+\quad+\quad+$

In vitro interaction

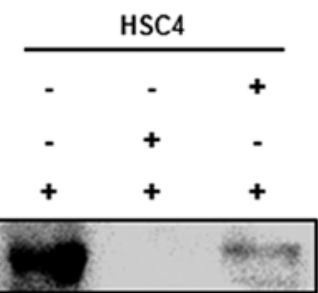

Figure 4. 7,8-DHF binds with Sp1. HN22 or HSC4 cell lysates were mixed with 7,8-DHF-conjugated Sepharose 4B beads or with Sepharose 4B beads alone, and the pulled-down proteins were analyzed by western blotting.
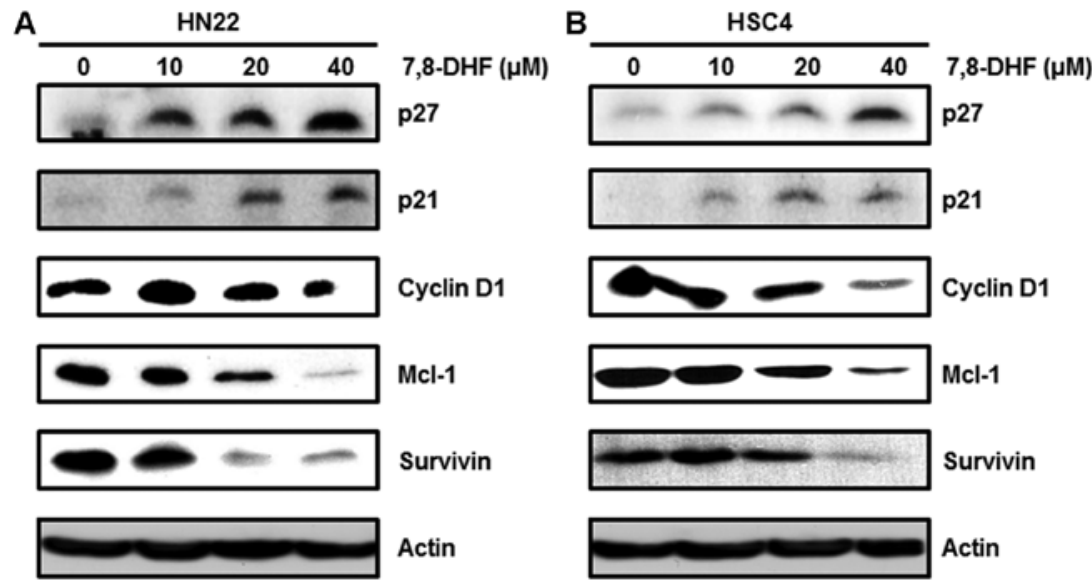

Figure 5. Effect of 7,8-DHF on Sp1 downstream target proteins. (A) HN22 and (B) HSC4 cells were treated with 10, 20 and $40 \mu \mathrm{M}$ 7,8-DHF for 48 h, and whole-cell extracts were prepared, separated on SDS-PAGE, and subjected to western blotting using p27, p21, cyclin D1, Mcl-1 and survivin antibodies. Actin was employed as a loading control. Results shown are representative of three independent experiments.

A

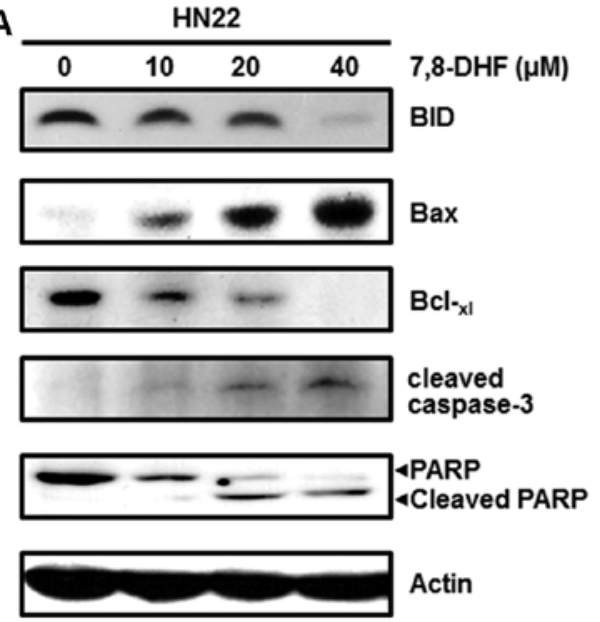

B

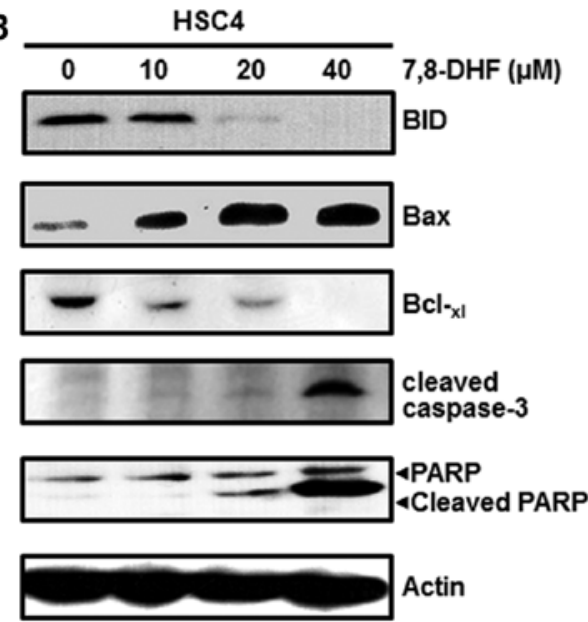

Figure 6. Effect of 7,8-DHF on apoptosis of oral squamous cell carcinoma. (A) HN22 and (B) HSC4 cells were treated 7,8-DHF (10, 20 and 40 $\mu \mathrm{M})$ for 48 h. The cell lysates were evaluated by western blot analysis with BID, Bax, Bcl- ${ }_{x 1}$, cleaved caspase-3, PARP and cleaved PARP antibodies. Equal loading of proteins was confirmed by western blotting of actin antibody. The results shown are representative of three independent experiments.

activities and the immune system (12,31-34). Among them, 7,8 -DHF is a novel compound isolated from the flavone family that appears to inhibit the proliferation of cancer cells (11), but its mechanism of action has not yet been investigated in detail.

In the present study, we examined the apoptotic effect of 7,8-DHF in OSCC. The effect of 7,8-DHF treatment on initiating apoptosis and cell cycle arrest in HN22 and
HSC 4 cells was determined by flow cytometry and DAPI staining. The percentage of sub- $\mathrm{G}_{1}$ phase cells increased in 7,8-DHF-treated cells compared with that in untreated control cells. Furthermore, the Annexin V assay revealed that 7,8-DHF induced early apoptosis (Fig. 2C). To determine the level of protein $\mathrm{Sp} 1$ expression due to 7,8-DHF treatment, HN22 and HSC4 cells were treated with various concentrations $(10,20$ and $40 \mu \mathrm{M}$ ) of 7,8-DHF for $48 \mathrm{~h}$ and different periods of time 
(12, 24, 36 and 48 h). As shown in Fig. 3A and B, treatment with 7,8-DHF induced a significant decrease in Sp1 protein expression levels in HN22 and HSC4 cells in a dose- and timedependent manner. Furthermore, Sp1 mRNA was suppressed by 7,8-DHF in both HN22 and HSC4 cells (Fig. 3C). The immunocytochemistry results revealed decreased $\mathrm{Spl}$ levels and increased levels of cleaved caspase- 3 in a dose-dependent manner in the HN22 and HSC4 cell lines (Fig. 3D). These results suggest that 7,8-DHF plays an important role as an antitumor agent by downregulation of Sp1, leading to apoptotic cell death in OSCC.

We examined a 7,8-DHF pull-down assay to identify 7,8-DHF molecular targets in tumorigenesis and confirmed that 7,8-DHF specifically binds with Sp1 (Fig. 4). To further characterize the effects of 7,8-DHF on Sp1, we analyzed the effect of p27, p21, cyclin D1, Mcl-1, and the survivin protein on Sp1 protein levels by western blot analysis (35-37). The results showed that levels of the Sp1 target proteins such as p27, p21, cyclin D1, Mcl-1, and survivin were inhibited by 7,8-DHF in a dose-dependent manner (Fig. 5). 7,8-DHF reduced BID and $\mathrm{Bcl}_{\mathrm{xl}}$, increased Bax, and cleaved caspase-3 and PARP, suggesting that 7,8-DHF regulates Sp1, ultimately leading to apoptotic cell death (Fig. 6). Our results indicate that 7,8-DHF may be capable of effectively treating cancer. Sp1 expression increases during cancer transformation and plays an important role in the maintenance and development of tumors. Downregulation of $\mathrm{Sp} 1$ is useful for treating tumor cells, and Spl overexpression induces the proliferation of cancer or transformed cells (22).

7,8-DHF clinical studies are necessary to describe the clinical applications and potential unexpected toxicities.

\section{Acknowledgements}

This study was supported by a grant from the Next-Generation BioGreen 21 Program (No. PJ00811604), Rural Development Administration, Republic of Korea.

\section{References}

1. Hamada T, Wakamatsu T, Miyahara M, et al: MUC4: a novel prognostic factor of oral squamous cell carcinoma. Int J Cancer 130: 1768-1776, 2012.

2. Rapidis AD, Gullane P, Langdon JD, Lefebvre JL, Scully C and Shah JP: Major advances in the knowledge and understanding of the epidemiology, aetiopathogenesis, diagnosis, management and prognosis of oral cancer. Oral Oncol 45: 299-300, 2009.

3. Scully C and Bagan J: Oral squamous cell carcinoma overview. Oral Oncol 45: 301-308, 2009.

4. Neville BW and Day TA: Oral cancer and precancerous lesions. CA Cancer J Clin 52: 195-215, 2002.

5. Mashberg A, Boffetta P, Winkelman R and Garfinkel L: Tobacco smoking, alcohol drinking, and cancer of the oral cavity and oropharynx among U.S. veterans. Cancer 72: 1369-1375, 1993.

6. Warnakulasuriya S: Global epidemiology of oral and oropharyngeal cancer. Oral Oncol 45: 309-316, 2009.

7. Sher DJ, Thotakura V, Balboni TA, et al: Treatment of oral cavity squamous cell carcinoma with adjuvant or definitive intensitymodulated radiation therapy. Int J Radiat Oncol Biol Phys 81: e215-e222, 2011

8. Sano D and Myers JN: Metastasis of squamous cell carcinoma of the oral tongue. Cancer Metastasis Rev 26: 645-662, 2007.

9. Zhang R, Kang KA, Piao MJ, et al: Preventive effect of 7,8-dihydroxyflavone against oxidative stress induced genotoxicity. Biol Pharm Bull 32: 166-171, 2009.

10. Jang SW, Liu X, Yepes M, et al: A selective TrkB agonist with potent neurotrophic activities by 7,8-dihydroxyflavone. Proc Natl Acad Sci USA 107: 2687-2692, 2010.
11. Chen J, Chua KW, Chua CC, et al: Antioxidant activity of 7,8-dihydroxyflavone provides neuroprotection against glutamate-induced toxicity. Neurosci Lett 499: 181-185, 2011.

12. Chahar MK, Sharma N, Dobhal MP and Joshi YC: Flavonoids: a versatile source of anticancer drugs. Pharmacogn Rev 5: 1-12, 2011.

13. Galati G, Teng S, Moridani MY, Chan TS and O'Brien PJ: Cancer chemoprevention and apoptosis mechanisms induced by dietary polyphenolics. Drug Metabol Drug Interact 17: 311-349, 2000.

14. Yang CS, Landau JM, Huang MT and Newmark HL: Inhibition of carcinogenesis by dietary polyphenolic compounds. Annu Rev Nutr 21: 381-406, 2001.

15. Huang WY, Cai YZ and Zhang Y: Natural phenolic compounds from medicinal herbs and dietary plants: potential use for cancer prevention. Nutr Cancer 62: 1-20, 2010.

16. Kilani-Jaziri S, Frachet V, Bhouri W, Ghedira K, ChekirGhedira L and Ronot X: Flavones inhibit the proliferation of human tumor cancer cell lines by inducing apoptosis. Drug Chem Toxicol 35: 1-10, 2012.

17. Davie JR, He S, Li L, et al: Nuclear organization and chromatin dynamics - Sp1, Sp3 and histone deacetylases. Adv Enzyme Regul 48: 189-208, 2008.

18. Li L and Davie JR: The role of Sp1 and Sp3 in normal and cancer cell biology. Ann Anat 192: 275-283, 2010.

19. Wan J, Carr BA, Cutler NS, Lanza DL, Hines RN and Yost GS: $\mathrm{Sp} 1$ and $\mathrm{Sp} 3$ regulate basal transcription of the human CYP2F1 gene. Drug Metab Dispos 33: 1244-1253, 2005.

20. Chu S and Ferro TJ: Sp1: regulation of gene expression by phosphorylation. Gene 348: 1-11, 2005.

21. Chuang JY, Wu CH, Lai MD, Chang WC and Hung JJ: Overexpression of $\mathrm{Sp} 1$ leads to p53-dependent apoptosis in cancer cells. Int J Cancer 125: 2066-2076, 2009.

22. Deniaud E, Baguet J, Mathieu AL, Pages G, Marvel J and Leverrier Y: Overexpression of Sp1 transcription factor induces apoptosis. Oncogene 25: 7096-7105, 2006.

23. Chen L, Liu Q, Qin R, et al: Amplification and functional characterization of MUC1 promoter and gene-virotherapy via a targeting adenoviral vector expressing hSSTR2 gene in MUC1positive Panc-1 pancreatic cancer cells in vitro. Int J Mol Med 15: 617-626, 2005.

24. Kong LM, Liao CG, Fei F, Guo X, Xing JL and Chen ZN: Transcription factor $S p 1$ regulates expression of cancer-associated molecule CD147 in human lung cancer. Cancer Sci 101: 1463-1470, 2010.

25. Garcia A, Zheng Y, Zhao C, et al: Honokiol suppresses survival signals mediated by Ras-dependent phospholipase D activity in human cancer cells. Clin Cancer Res 14: 4267-4274, 2008.

26. Deng J, Qian Y, Geng L, et al: Involvement of p38 mitogenactivated protein kinase pathway in honokiol-induced apoptosis in a human hepatoma cell line (hepG2). Liver Int 28: 1458-1464, 2008.

27. Urusova DV, Shim JH, Kim DJ, et al: Epigallocatechin-gallate suppresses tumorigenesis by directly targeting Pin1. Cancer Prev Res 4: 1366-1377, 2011.

28. Shin JA, Kim JJ, Choi ES, et al: In vitro apoptotic effects of methanol extracts of Dianthus chinensis and Acalypha australis L. targeting specificity protein 1 in human oral cancer cells. Head Neck 35: 992-998, 2013.

29. Dasari A, Bartholomew JN, Volonte D and Galbiati F: Oxidative stress induces premature senescence by stimulating caveolin-1 gene transcription through p38 mitogen-activated protein kinase/ Sp1-mediated activation of two GC-rich promoter elements. Cancer Res 66: 10805-10814, 2006.

30. Jutooru I, Chadalapaka G, Sreevalsan S, et al: Arsenic trioxide downregulates specificity protein $(\mathrm{Sp})$ transcription factors and inhibits bladder cancer cell and tumor growth. Exp Cell Res 316: 2174-2188, 2010.

31. Curin Y and Andriantsitohaina R: Polyphenols as potential therapeutical agents against cardiovascular diseases. Pharmacol Rep 57 Suppl: 97-107, 2005.

32. Pan $\mathrm{MH}$ and Ho CT: Chemopreventive effects of natural dietary compounds on cancer development. Chem Soc Rev 37: 2558-2574, 2008

33. Prasad S, Phromnoi K, Yadav VR, Chaturvedi MM and Aggarwal BB: Targeting inflammatory pathways by flavonoids for prevention and treatment of cancer. Planta Med 76: 1044-1063, 2010.

34. Guo W, Kong E and Meydani M: Dietary polyphenols, inflammation, and cancer. Nutr Cancer 61: 807-810, 2009. 
35. Blume SW, Snyder RC, Ray R, Thomas S, Koller CA and Miller DM: Mithramycin inhibits SP1 binding and selectively inhibits transcriptional activity of the dihydrofolate reductase gene in vitro and in vivo. J Clin Invest 88: 1613-1621, 1991.

36. Chintharlapalli S, Papineni S, Lei P, Pathi S and Safe S: Betulinic acid inhibits colon cancer cell and tumor growth and induces proteasome-dependent and -independent downregulation of specificity proteins $(\mathrm{Sp})$ transcription factors. BMC Cancer 11: 371,2011
37. Pietrzak $\mathrm{M}$ and Puzianowska-Kuznicka M: p53-dependent repression of the human MCL-1 gene encoding an anti-apoptotic member of the BCL-2 family: the role of Spl and of basic transcription factor binding sites in the MCL-1 promoter. Biol Chem 389: 383-393, 2008. 